\title{
Use of a neck brace minimizes double-lumen tube displacement during patient positioning
}

\author{
[L'usage d'un collet cervical réduit le déplacement du tube à double lumière pen- \\ dant le positionnement du patient]
}

Tae-Gyoon Yoon MD, ${ }^{*}$ Hye-Won Chang MD, $†$ Ho-Geol Ryu MD, ${ }^{*}$ Tae-Dong Kwon MD, ${ }^{*}$ Jae-Hyon Bahk MD

Purpose: When patients are moved from the supine to the lateral decubitus position, the double-lumen endobronchial tube (DLT) is often displaced. The aim of this study was to determine whether a DLT is displaced when there are no movements of the head and neck.

Methods: One hundred patients scheduled for elective thoracic surgery were randomly divided into control and brace groups. Only a left-sided DLT was used during the study. All patients in the brace group wore a neck collar before the positional change. Using a fibreoptic bronchoscope, the distance from the tracheal opening to the main carina and from the bronchial opening to the bronchial carina was measured in the supine and lateral decubitus positions.

Results: Displacement of the DLT (mean \pm SD) during a change from the supine to the lateral decubitus position was greater in the control group $(6.3 \pm 5.5 \mathrm{~mm}$ in the trachea; $2.4 \pm 3.6 \mathrm{~mm}$ in the bronchus) than in the brace group $(2.2 \pm 3.9 \mathrm{~mm}$ in the trachea; $0.6 \pm 3.1 \mathrm{~mm}$ in the bronchus); $(P<0.00 \mathrm{I})$. The incidence of clinically significant displacement, greater than $5 \mathrm{~mm}$ from the initial correct position, was higher in the control group than in the brace group (48\% vs I $2 \%, P<0.00$ I).

Conclusion: By restricting head and neck movements with a neck brace, the DLT displacement could be minimized while positioning patients for thoracotomy. The main cause of the DLT displacement during lateral positioning appears to be related to movement of the head and neck.

Objectif : Quand les patients sont changés de position, du décubitus dorsal à latéral, le tube endobronchique à double lumière (TDL) est souvent déplacé. Notre but était de découvrir si un TDL est déplacé quand il n'y a aucun mouvement de la tête et du cou.
Méthode : Cent patients devant subir une intervention chirurgicale thoracique réglée ont été répartis en groupes témoin et collet cervical (CC). Seul un TDL gauche a été utilisé. Tous les patients du groupe CC portaient un collet cervical avant le changement de position. À l'aide d'un fibroscope bronchique, la distance entre l'ouverture de la trachée et la carène principale et entre l'ouverture bronchique et la carène bronchique a été mesurée en décubitus dorsal et latéral.

Résultats : Le déplacement du TDL (moyenne \pm écart type) pendant un changement de position, du décubitus dorsal à latéral, a été plus grand dans le groupe témoin (6,3 \pm 5,5 mm dans la trachée ; 2,4 \pm 3,6 $\mathrm{mm}$ dans la bronche) que dans le groupe CC (2,2 $\pm 3,9$ mm dans la trachée ; 0,6 $\pm 3,1 \mathrm{~mm}$ dans la bronche); $(P<0,001)$. L'incidence d'un déplacement cliniquement significatif, plus grand que $5 \mathrm{~mm}$ de la position initiale correcte, a été plus élevée dans le groupe témoin que dans le groupe CC (48\% vs $12 \%, P<0,001$ ).

Conclusion : En restreignant les mouvements de la tête et du cou avec un collet cervical, le déplacement du TDL peut être minimisé quand on installe les patients pour la thoracotomie. La principale cause de déplacement du TDL chez le patient en décubitus latéral semble reliée au mouvement de la tête et du cou.

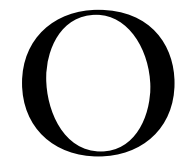

NE-LUNG ventilation (OLV) is required for lung surgery, some other fields of thoracic surgery and emergency situations requiring lung separation. The deleterious consequences of a malpositioned doublelumen endobronchial tube (DLT) can be substantial, even life-threatening.

From the Departments of Anesthesiology, Seoul National University Hospital, ${ }^{*}$ Seoul National University College of Medicine; and the Kangnam Saint Mary's Hospital, $†$ The Catholic University of Korea, Seoul, Korea.

Address correspondence to: Dr. Jae-Hyon Bahk, Department of Anesthesiology, Seoul National University Hospital, Seoul National

University College of Medicine, 28 Yongon-Dong, Chongno-Gu, Seoul, Korea 110-744; Phone: 82-2-2072-2818; Fax: 82-2-747-5639;

E-mail: bahkjh@snu.ac.kr

This study was performed at Seoul National University Hospital, and was supported solely from departmental sources.

Presented in part at the American Society of Anesthesiologists Annual meeting, Las Vegas, Nevada, USA, October 25, 2004.

Accepted for publication August 26, 2004.

Revision accepted January 19, 2005. 
While patients are moved from the supine to the lateral decubitus position, proximal displacement predominates, ${ }^{1-4}$ but distal displacement may also occur. $^{1-3}$ In a prior thoracotomy case (unpublished observation), whose entire cervical spine was affected by ankylosing spondylitis, however, we observed that the Univent ${ }^{\circledR}$ tube and bronchial blocker (Fuji Systems Corporation, Tokyo, Japan) were not displaced during the lateral positioning. Flexion and extension of the neck can cause considerable movement of the single-lumen tube and the DLT., 5 Consequently, we hypothesized that movement of the head and neck was the main cause of the DLT displacement occurring during changes in position.

The dynamics of the carinal downward shift due to gravity have been described during lateral positioning. ${ }^{7}$ The angle of the tracheal axis with the left main bronchus increases greatly when patients are moved from the supine to the left lateral position. ${ }^{8}$ The increased distance between the tracheal tube tip and the main carina with lateral positioning may be attributed in part to this downward shift of the tracheal carina. ${ }^{2}$

The purpose of our study was to determine whether a DLT is displaced when movement of the head and neck is prevented, and to assess how gravity affects DLT position by comparing displacement between the right and left lateral positions.

\section{Methods}

With the approval of the hospital Review Board and after obtaining patient informed consent, 100 elective thoracic surgical patients, aged 16 to $77 \mathrm{yr}$, were enrolled for this study. Patients who absolutely required a right-sided DLT, presented an intraluminal lesion of the left bronchus, and presented a very distorted anatomy of the tracheobronchial tree on chest radiograph were excluded. Patients with a prior thoracotomy, pleural effusion on chest radiograph, or the possibility of pleural adhesions (such as tuberculosis or previous chest tube insertion) were also excluded.

Patients were randomly divided into two groups. One group of patients wore neck collars (Miami J® Collar; Jerome Medical, Moorestown, NJ, USA) before adjusting the position of the DLT in the supine position and during the change from the supine to the lateral decubitus position (brace group). The control group did not wear a neck collar. The two groups were further subdivided into the right and the left lateral decubitus positions.

Routine practice to prevent dislodgment of the DLT during changes in position consists of holding onto the DLT at the level of the incisors and keeping the head immobile in the neutral or slightly flexed position. ${ }^{9}$ All anesthesiologists were instructed to make every effort to minimize head and neck movement during lateral positioning. According to proto$\mathrm{col}$, the head and neck were aligned with the thoracic vertebral column to prevent the neck from flexing laterally. Anesthesiologists who had more than three years of experience, but did not know the purpose of this study, supervised all the procedures.

The DLT size was selected following Hannallah's and Chow's method. ${ }^{10,11}$ After induction of anesthesia, patients were intubated with a disposable polyvinyl chloride left-sided DLT (Broncho-Cath ${ }^{\circledR}$, Mallinckrodt Medical Ltd., Athlone, Ireland) using a conventional method. ${ }^{9}$ Subsequently, the head was returned to the neutral position and a Miami ${ }^{\circledR}$ neck collar was applied in the brace group. The position of the DLT was adjusted by an independent senior resident, who was not involved in the study, using a fibreoptic bronchoscope (FOB; Olympus LF-2, Olympus Optical Co., Tokyo, Japan). The endobronchial cuff was positioned just below the carina, without herniation.

After adjusting the position of the DLT in the supine position, the distance from the opening of the tracheal lumen to the main carina was measured with a FOB passing through the tracheal lumen. ${ }^{2}$ The distance from the distal tip of the bronchial lumen to the left bronchial carina was measured with the FOB passing through the bronchial lumen (Figure). The distance was measured as described previously. ${ }^{12}$ Briefly, the tracheal carina was visualized at the tip of the FOB and a piece of tape was placed on the FOB at the point where it entered the self-sealing diaphragm in the elbow connector. Subsequently, the FOB was withdrawn until the proximal opening of the tracheal lumen, indicated by the vertical black mark on the DLT, was at the tip of the FOB and another piece of tape was placed on the FOB at the point of entry into the self-sealing diaphragm. The distance between the two pieces of tape was measured to the nearest $1-\mathrm{mm}$ interval. The displacement during positional change was defined as the difference $(\mathrm{mm})$ in the distance between the two pieces of tape. To provide a qualitative measure, clinically significant displacement was defined when the DLT was displaced by more than 5 $\mathrm{mm}$ from the initial correct position, regardless of the direction of displacement. ${ }^{1}$ The second set of measurements was taken with the axillary rolls in place after the change in position. The third set was taken after extending the operated, nondependent thorax by flexing the operating table.

The data are expressed as mean \pm SD (range). Positive values for displacements refer to proximal movement and negative values to distal movement. 
TABLE I Patient characteristics

\begin{tabular}{|c|c|c|c|c|}
\hline & \multicolumn{2}{|c|}{ Control group } & \multicolumn{2}{|c|}{ Brace group } \\
\hline & $\begin{array}{l}\text { Right lateral } \\
\text { position }\end{array}$ & $\begin{array}{l}\text { Left lateral } \\
\text { position }\end{array}$ & $\begin{array}{l}\text { Right lateral } \\
\text { position }\end{array}$ & $\begin{array}{l}\text { Left lateral } \\
\text { position }\end{array}$ \\
\hline Weight (kg) & $\begin{array}{l}62.2 \pm 9.9 \\
(44-80)\end{array}$ & $\begin{array}{l}67.3 \pm 9.8 \\
(47-80)\end{array}$ & $\begin{array}{l}64.9 \pm 10.0 \\
(45-85)\end{array}$ & $\begin{array}{l}65.6 \pm 11.1 \\
(46-78)\end{array}$ \\
\hline Gender (male:female) & $17: 8$ & $15: 10$ & $16: 9$ & $16: 9$ \\
\hline Double-lumen tube size & & & & \\
\hline 35 & 7 & 11 & 8 & 8 \\
\hline 37 & 11 & 11 & 12 & 10 \\
\hline 39 & 6 & 3 & 5 & 6 \\
\hline 41 & 1 & 0 & 0 & 1 \\
\hline
\end{tabular}

$n=25$ in each of the four subgroups. Values are expressed as mean \pm SD (range) or number of patients. No differences in age, weight, height, gender, and double-lumen tube size between groups.

TABLE II Tracheal and bronchial displacement of the left double-lumen tubes while patients were moved from the supine to the lateral decubitus position with the operated, nondependent thorax extended

\begin{tabular}{lllll}
\hline & \multicolumn{1}{c}{ Control group* $^{*}$} & \multicolumn{2}{c}{ Brace group } \\
$\begin{array}{l}\text { Displacement of the } \\
\text { double-lumen tubet }\end{array}$ & $\begin{array}{l}\text { Right lateral } \\
\text { position }\end{array}$ & $\begin{array}{l}\text { Reft lateral } \\
\text { position }\end{array}$ & position lateral & $\begin{array}{l}\text { Left lateral } \\
\text { position }\end{array}$ \\
\hline$\Delta$ Tracheal $(\mathrm{mm})$ & $6.4 \pm 4.7$ & $6.3 \pm 6.1$ & $2.5 \pm 4.2$ & $1.8 \pm 3.3$ \\
& $(-1-+15)$ & $(-5-+20)$ & $(-5-+10)$ & $(-5-+8)$ \\
$\Delta$ Bronchial $(\mathrm{mm})$ & $3.4 \pm 3.7$ & $1.6 \pm 5.1$ & $0.1 \pm 3.4$ & $1.0 \pm 2.7$ \\
& $(-5-+10)$ & $(-7-+10)$ & $(-10-+5)$ & $(-5-+5)$ \\
\hline
\end{tabular}

$n=25$ in each of the four subgroups. Values are expressed as mean \pm SD (range). Positive values for displacements refer to proximal movement and negative values to distal movement. ${ }^{\star} P<0.001$ vs brace groups. $\dagger P<0.05$ between tracheal and bronchial displacements.

TABLE III Incidence of clinically significant displacement of the left double-lumen tubes while patients were moved from the supine to the lateral decubitus position with the operated, nondependent thorax extended

\begin{tabular}{lllll}
\hline & \multicolumn{1}{c}{ Control group } & \multicolumn{2}{c}{ Brace group } \\
$\begin{array}{l}\text { Incidence of clinically } \\
\text { significant displacement }\end{array}$ & $\begin{array}{l}\text { Right lateral } \\
\text { position }\end{array}$ & $\begin{array}{l}\text { Left lateral } \\
\text { position }\end{array}$ & $\begin{array}{l}\text { Right lateral } \\
\text { position }\end{array}$ & $\begin{array}{l}\text { Left lateral } \\
\text { position }\end{array}$ \\
\hline Proximal direction (\%) & $9 / 25(36)$ & $10 / 25(40)$ & $3 / 25(12)$ & $3 / 25(12)$ \\
Distal direction (\%) & $4 / 25(16)$ & $1 / 25(4)$ & $0 / 25(0)$ & $0 / 25(0)$ \\
Overall $(\%)^{*}$ & $13 / 25(52)$ & $11 / 25(44)$ & $3 / 25(12)$ & $3 / 25(12)$ \\
\hline
\end{tabular}

Clinically significant displacement was defined as displacement longer than $5 \mathrm{~mm}$ from the initial correct position regardless of the direction of displacement. ${ }^{*} P<0.001$ between control and brace groups.

Statistical differences in height, weight, and age were assessed by analysis of variance (ANOVA), gender differences by the Chi-square test, and the DLT size by Fisher's exact test among the subgroups. Displacement of the DLT was compared with ANOVA followed by Student-Newman-Keuls multiple comparison test. The incidence of clinically significant displacement was compared between groups with a Chi-square test. SPSS software (version 9.0; SPSS Inc, Chicago, IL, USA) was used. A $P$-value $<0.05$ was considered statistically significant.

\section{Results}

There were no differences in the age, weight, height or gender of patients in the four subgroups (Table I): 35 of the patients underwent lobectomy; ten, pneu- 
monectomy; 42, video-assisted thoracoscopic surgery; eight, Ivor-Lewis operation (esophagectomy and esophagogastrostomy); and five, exploratory thoracotomy. When patients were moved from the supine to the lateral decubitus position, displacement of the DLT was greater in the control group $[6.3 \pm 5.5(-5$ $-+20) \mathrm{mm}$ in the trachea; $2.4 \pm 3.6(-7-+10) \mathrm{mm}$ in the bronchus] than in the brace group $[2.2 \pm 3.9(-5$ $-+10) \mathrm{mm}$ in the trachea; $0.6 \pm 3.1(-10-+5) \mathrm{mm}$ in the bronchus $] ;(P<0.001)$. Displacement of the DLT on the tracheal side was greater than on the bronchial side $(P<0.05)$; (Table II). The incidence of clinically significant displacement in the control group was higher than in the brace group $(48 \%$ vs $12 \%, P<$ 0.001 ); (Table III). There were no statistical differences in displacement of the DLT and the incidence of the clinically significant displacement regarding the dependent side in the lateral decubitus position (Tables II and III). Tracheal and bronchial displacements while moving patients from the supine to the simple lateral decubitus positions $[3.6 \pm 4.6(-5-+18)$ and $2.7 \pm 3.6(-7-+10) \mathrm{mm}$, respectively] were not different from those observed while moving patients from the supine to the lateral decubitus positions with the operated, nondependent thorax extended $[4.0 \pm$ $5.0(-5-+20)$ and $1.3 \pm 3.9(-10-+10) \mathrm{mm}$, respectively], i.e., flexion of the operating table did not produce further displacement.

\section{Discussion}

While positioning patients for thoracotomy, restriction of head and neck movements with a brace minimized displacement of the DLT. Since there was no difference in the displacement of the DLT depending on the dependent side after positioning, gravity does not appear to have a major effect on the position of the DLT.

Intubation is usually accomplished under direct laryngoscopy with the head on a pillow, with some degree of neck flexion and head extension depending on the occipital prominence and the height of the pillow. During lateral positioning, in comparison with the supine position, neck flexion disappears, resulting in a relative extension of the neck. Additionally, the occipital prominence that elevates the head in the supine position may cause it to extend because of the weight of the head in the lateral decubitus position. All such changes in the position of the head and neck may cause a proximal displacement of the DLT.

Efforts have been made to maintain the same chinto-xiphoid distance to ensure the same head and neck position after turning to the lateral decubitus position. ${ }^{2}$ However, as the head and neck moves in a com-

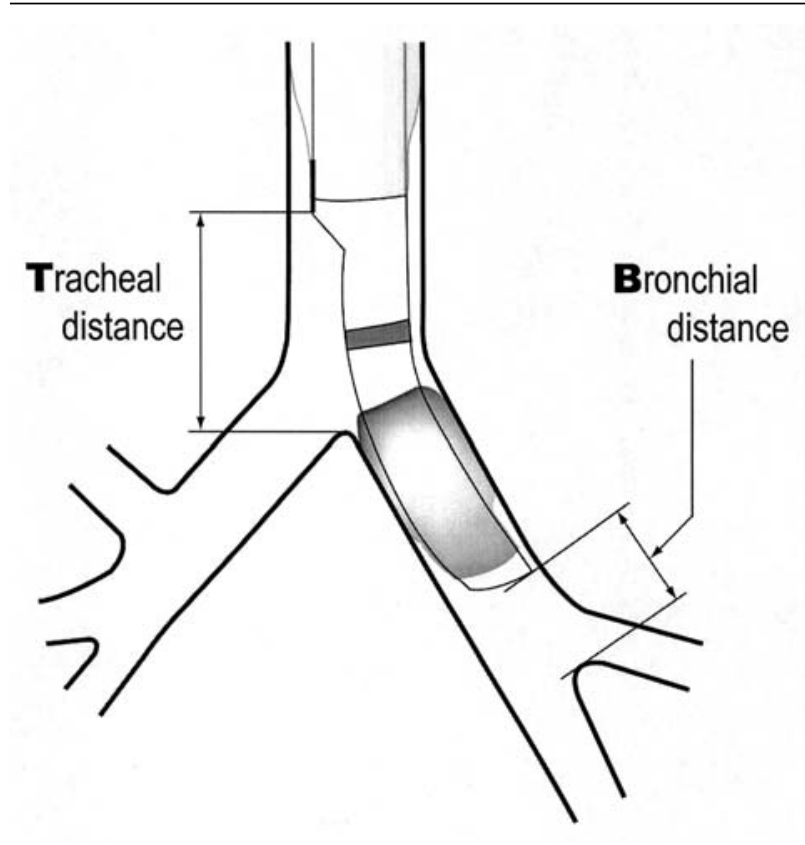

FIGURE Measurement of the distances from the opening of the tracheal lumen to the main carina (tracheal distance) and from the tip of the bronchial lumen to the bronchial carina (bronchial distance).

bination of axes, ${ }^{13}$ movement of the head and neck may still occur irrespective of the chin-to-xiphoid distance. Displacement in the brace group in our study was shorter than the distance of approximately $10 \mathrm{~mm}$ reported by Desiderio and colleagues, ${ }^{2}$ although the chin-to-xiphoid distance appeared comparable. The Miami J® neck collar used in our study decreases the motion of the neck to $24 \%$ of the normal flexion, $30 \%$ of the normal extension, $27 \%$ of the normal combined flexion-extension and $49 \%$ of the normal lateral flexion. ${ }^{14}$ Thus, despite the use of a neck collar, some movement of the head and neck was unavoidable resulting in displacements of the DLT during change in position.

The Sher-I-Broth ${ }^{\mathrm{TM}}$ DLT (Sheridan, Argyle, NY, USA) was displaced in 74 to $80 \%$ of cases during lateral positioning, regardless of endobronchial cuff inflation. ${ }^{2}$ The displacement was predominantly in the upward direction. ${ }^{2}$ After the lateral positioning of patients with the Broncho-Cath ${ }^{\circledR}$ DLT, malposition requiring repositioning or resulting in movement longer than $5 \mathrm{~mm}$ has been observed in $46.5 \%$ and $53 \%$ of cases. ${ }^{1,3}$ After patient positioning, displacement of the DLT was observed in $52.5 \%{ }^{4}$ In our 
study, the clinically significant displacement of the DLT in the control group was $48 \%$, which is comparable to the incidence reported previously. ${ }^{1,3,4}$

We speculated that some displacement of the DLT would be inevitable, due to the weight of the lung and mediastinum. However, the dependent side had no noticeable effect on DLT displacement. Both tracheal and bronchial displacements were minimized by the use of a neck brace, but tracheal displacement was still more prominent than bronchial displacement. This suggests that movement of the head and neck has a more important effect on the displacement of the trachea than on the mainstem bronchus. Further, flexing the operating table for surgical exposure did not displace the DLT significantly.

Position of the DLT during anesthesia may be altered by surgical manipulations, patient coughing, moving the head or neck, or moving the entire body. ${ }^{15}$ Since proximal displacement predominates during lateral positioning, a 0.5 to $1 \mathrm{~cm}$ deeper than the correct position may be recommended before patient positioning. ${ }^{3,4}$ Displacement of the DLT during lateral decubitus positioning is caused primarily by movement (extension) of the head and neck. Therefore, we recommend making every effort to minimize movement of the head and neck during the anesthetic management of these patients. Clinically, wearing a neck brace may be recommended during lateral decubitus positioning. This study suggests the possibility that use of a neck brace might also help in preventing displacement of a right-sided DLT, that has a narrow margin of safety, but this hypothesis will require a further, specific study.

\section{References}

1 Klein U, Karzai W, Bloos F, et al. Role of fiberoptic bronchoscopy in conjunction with the use of doublelumen tubes for thoracic anesthesia. Anesthesiology 1998; 88: 346-50.

2 Desiderio DP, Burt M, Kolker AC, Fischer ME, Reinsel $R$, Wilson RS. The effects of endobronchial cuff inflation on double-lumen endobronchial tube movement after lateral decubitus positioning. J Cardiothorac Vasc Anesth 1997; 11: 595-8.

3 Fortier G, Coté D, Bergeron C, Bussières JS. New landmarks improve the positioning of the left BronchoCath $^{\mathrm{TM}}$ double-lumen tube-comparison with the classic technique. Can J Anesth 2001; 48: 790-4.

4 Cheng KS, Wu RS, Tan PP. Displacement of doublelumen tubes after patient positioning (Letter). Anesthesiology 1998; 89: 1282-3.

5 Conrardy PA, Goodman LR, Lainge F, Singer MM. Alteration of endotracheal tube position. Flextion and extension of the neck. Crit Care Med 1976; 4: 8-12.
6 Gray $H$. The respiratory system. In: Clemente C (Ed.). Anatomy of the Human Body, 13th ed. Philadelphia: Lea \& Febriger; 1985: 1380-98.

7 Yahagi N, Furuya H, Matsui J, Sai $\Upsilon$, Amakata $\Upsilon$, Kumon K. Improvement of the left Broncho-Cath double-lumen tube (Letter). Anesthesiology 1994; 81: 781-2.

8 Saito $S$, Dohi S, Naito $H$. Alteration of double-lumen endobronchial tube position by flexion and extension of the neck (Letter). Anesthesiology 1985; 62: 696-7.

9 Benumof JL. Separation of the two lungs (doublelumen tube and bronchial blocker intubation). In: Benumof JL (Ed.). Anesthesia for Thoracic Surgery, 2nd ed. Philadelphia: W.B. Saunders; 1995: 330-89.

10 Hannallah M, Benumof JL, Silverman PM, Kelly LC, Lea $D$. Evaluation of an approach to choosing a left double-lumen tube size based on chest computed tomographic scan measurement of left mainstem bronchial diameter. J Cardiothorac Vasc Anesth 1997; 11: 168-71.

11 Chow MY, Liam BL, Thng CH, Chong BK. Predicting the size of a double-lumen endobronchial tube using computed tomographic scan measurements of the left main bronchus diameter. Anesth Analg 1999; 88: 302-5.

12 Benumof JL, Partridge BL, Salvatierra C, Keating J. Margin of safety in positioning modern double-lumen endotracheal tubes. Anesthesiology 1987; 67: 729-38.

13 Tucci SM, Hicks JE, Gross EG, Campbell W, Danhoff J. Cervical motion assessment: a new, simple and accurate method. Arch Phys Med Rehabil 1986; 67: 225-30.

14 Askins V, Eismont FJ. MD. Efficacy of five cervical orthoses in restricting cervical motion. A comparison study. Spine 1997; 22: 1193-8.

15 Riley RH, Marples IL. Relocation of a double-lumen tube during patient positioning (Letter). Anesth Analg 1992; 75: 1070-5. 